University of Nebraska - Lincoln

DigitalCommons@University of Nebraska - Lincoln

Architectural Engineering -- Faculty Publications

Architectural Engineering and Construction,

Durham School of

2011

\title{
Addressable And Energy Management System For The Built Environment (I)
}

\author{
Mahmoud Alahmad \\ University of Nebraska - Lincoln, malahmad2@unl.edu \\ Hosen Hasna $\mathrm{HH}$ \\ University of Nebraska-Lincoln, hhasna@unomaha.edu \\ Evans Sordiashie \\ University of Nebraska-Lincoln, sord.evans@huskers.unl.edu
}

Follow this and additional works at: https://digitalcommons.unl.edu/archengfacpub

Part of the Architectural Engineering Commons

Alahmad, Mahmoud; Hasna, Hosen HH; and Sordiashie, Evans, "Addressable And Energy Management System For The Built Environment (I)" (2011). Architectural Engineering -- Faculty Publications. 55. https://digitalcommons.unl.edu/archengfacpub/55

This Article is brought to you for free and open access by the Architectural Engineering and Construction, Durham School of at DigitalCommons@University of Nebraska - Lincoln. It has been accepted for inclusion in Architectural Engineering -- Faculty Publications by an authorized administrator of DigitalCommons@University of Nebraska Lincoln. 


\section{ADDRESSABLE AND ENERGY MANAGEMENT SYSTEM FOR THE BUILT ENVIRONMENT (I)}

\author{
Mahmoud Alahmad, PhD, P.E \\ Durham School of Architectural \\ Engineering and Construction \\ University of Nebraska-Lincoln \\ Omaha, Nebraska, U.S.A. \\ malahmad2@unl.edu
}

\author{
Hosen Hasna, MS Student \\ Durham School of Architectural \\ Engineering and Construction \\ University of Nebraska-Lincoln \\ Omaha, Nebraska, U.S.A. \\ hhasna@unomaha.edu
}

\author{
Evans Sordiashie, MS Student \\ Durham School of Architectural \\ Engineering and Construction \\ University of Nebraska-Lincoln \\ Omaha, Nebraska, U.S.A. \\ Sord.evans@huskers.unl.edu
}

\begin{abstract}
The increasing awareness for a cleaner earth has created more interests in the electric vehicle (EV) technology. Electric vehicles (EVs) will not only cause a reduction in our current greenhouse gas emissions, but also stop or reverse the trend at which our natural resources are being depleted. However, the introduction of the EVs into our societies will still require energy usage in the form of electricity. Integration of charging infrastructures will eventually be required in the built environment for these vehicles. This will add to the current energy consumption in the built environment which will mean more emission of $\mathrm{CO}_{2}, \mathrm{NO}_{2}$ etc., in the electrical power generation process. Therefore, this research looks at reducing energy wastage as a way of saving energy for the future integration of EVs into the built environment.
\end{abstract}

Keywords- Electric Vehicles, Power distibution, Time Domain Reflectometry, Non-Intrusive Load Monitoring, Neural Network.

\section{INTRODUCTION}

Transportation plays a very important role in our societies. It is the means by which we are able to overcome huge distances between us and points of interest on the globe. Industries and businesses depend heavily on transportation to send and receive products for processing and distribution to consumers. However, most current transportation technologies or systems are powered by non-renewable energy sources which have various adverse effects on environment. Some of these effects are greenhouse gas emissions, air and water bodies pollution, to mention a few.

To solve the environmental problems from these nonrenewable energies, current transportation technologies are focusing on design and manufacture of electric vehicles (EVs). Introduction of EVs will reduce emission of greenhouse gases, air pollution, depletion of our natural resources etc. and will have a positive impact on our environment as a whole. But the introduction of EVs as an eco-friendly means for transportation in our societies will still require energy usage in the form of electricity. Integration of charging infrastructures will sooner or later be required in the built environment for these vehicles. This will in turn add to the current energy consumption in the built environment hence more emission of $\mathrm{CO}_{2}, \mathrm{NO}_{2}$ etc., in the electrical power generation process.

The electric power sector is experiencing a major shift in its generation, transmission and distribution system, in an effort to reduce $\mathrm{CO}_{2}$ emissions, increase the use of renewable sources for a sustainable energy future and conserve precious resources by reducing energy consumption. The distribution system particularly plays a role in the built environment as it is an enabling product, an intangible necessity used to power our systems. The 2010 Annual Energy Outlook indicates a 14\% increase in U.S. primary energy consumption from 2008 to 2035 , an average annual growth rate of $0.5 \%$. Further, $\mathrm{CO}_{2}$ emissions are projected to increase by $0.3 \%$ per year for the same time frame. This increase is mostly due to the electric power and transportation sectors. According to United States Green Building Council (USGBC), the built environment in the United States accounts for $72 \%$ of electricity consumption, $39 \%$ of energy use, $38 \%$ of all $\mathrm{CO}_{2}$ emissions, $40 \%$ of raw materials use, $30 \%$ of waste output (136 million tons annually), and $14 \%$ of potable water consumption [2]. To reduce electricity consumption, energy efficiency programs emphasize the use of energy-saving technologies and design practices, promoting the adage "Energy saved is energy earned." A reduction of just five percent in global energy use would save the equivalent of more than 10 million barrels of oil per day and provide enough energy to power Australia, Mexico, and the United Kingdom [3].

Active research into energy conservation in the built environment is focusing on more efficient and sustainable systems and energy consumption awareness and behavior change. This behavior change is more prominent in the residential sector with Advanced Metering Initiatives and Infrastructure (AMI) being developed to empower the user and to facilitate the future of the smart grid. Most research activities are addressing the energy consumption from a top approach, i.e. looking at total consumption to influence behavior. A 2010 study by American Council for an Energy-Efficient Economy (ACEEE) of 57 energy conservation projects from 1970-2010 found that feedback devices alone are unlikely to maximize energy savings [4]. Hence, there is a need to focus on creative and promising methods to encourage energy efficient lifestyles. 
For example, identification of specific load and location have recently emerged to develop smart home/building to conserve energy and provide for comfortable living and working environment.

Toward a smart built environment, this research focuses on addressing energy needs using a bottom-up approach. The focus will be on consumption and conservation at the electrical node, where an electrical node is a point on the electrical wiring system at which electrical current is taken to supply utilization equipment (load). Investigations are being done to develop non-intrusive and novel methods to identify the location of each node and the potential of energy saving of the connected loads. Information from these investigations will be used for modeling, simulation and analysis to enable innovations in building information modeling (BIM), energy consumption performance and conservation, energy recovery using impulse saving behavior at the residential level and demand side energy management at the commercial/utility level.

Some emerging technologies [5][6][7], employ a lot of hardware additions to existing circuitry to achieve the intended goal of this research. The ultimate goal of this research is to be able to identify and locate energy consumption points with very minimal hardware additions to existing electrical circuitry in the built environment. Remote identification of load points or location is being investigated through Time Domain Reflectometry technology and fault detection threw energy prediction or the Model Kw

Fig.1 shows a block diagram of the proposed addressable power distribution and energy management system.

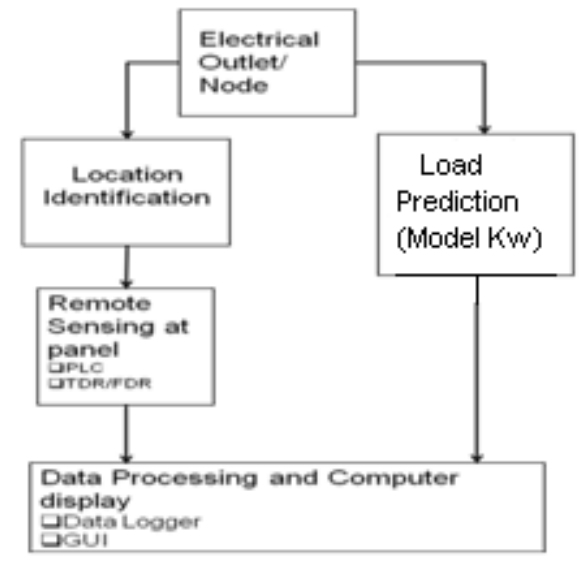

Figure 1: Block diagram of the Proposed Addressable and Energy Management System

\section{LOAD LOCATION IDENTIFICATION}

The identification of load locations is being investigated through Time Domain Reflectometry (TDR) [9], Power Line Communication (PLC) [13], [14] and Energy Harvesting [8],[15] with focus on TDR. Time Domain Reflectometry (TDR) is used to locate faults in all types of metallic paired cables [8]. It is used to locate cabling problems such as sheath faults, broken conductors, water damage, loose connectors, shorted conductors, smashed cables, crimps, system components and a variety of cable faults.

TDR technology is based on sending shaped pulse waveform along the electrical conductor (wire) [9], [10], [11], [12]. The wave propagates down the conductor and sends back a reflected signal to the TDR source (in the electrical panel) when it experiences an impedance change on the conductor. The distance from the point of reflection back to the TDR gives a unique temporal signature that can be used to determine the status of the conductor. This concept is being investigated to identify the location of each node along the electrical network by continuously sending a unique waveform onto the conductor linking all the nodes. Once a node's characteristic is modified, i.e. a load is connected, the location will be identified using the corresponding reflected signal back to the TDR. The reflected signal will be predefined in a lookup table matching the distances of each node from the TDR source in the panel level. This method of load location identification will eliminate the modification of existing nodes (outlets) in existing homes.

The propagation of the wave along the conductor depends on the Velocity of Propagation (VOP) or Velocity Factor of the conductor medium. Where velocity factor (VF) of the conductor is the speed at which a wave travels through the conductor, relative to the speed of light. In the event that reflection occurs, the difference in time measurement of when the pulse is sent and reflected back is recorded. This difference in time is used with the velocity factor (VF) of the cable to determine the distance at which the pulse was reflected back. The TDR display will show a rise in reflected signal amplitude when impedance change is higher than that of the TDR and will in drop signal amplitude when the impedance change is lower than that of the TDR. Points of reflection along the conductor will potentially be the various electrical nodes or outlets with connected loads. When an outlet is not in use, reflected pulse signal display on TDR apparatus will only show a continuous signal without any reflection on the conductor. In the event that a particular outlet is in use (change in impedance) at any time, the TDR will display the location of the node with a reflected signal corresponding to distance of the node to the TDR. The TDR technology used on live wires is Spread Spectrum Time Domain Reflectometry (SS TDR). Fig. 2 shows the proposed model of the addressable power distribution system.

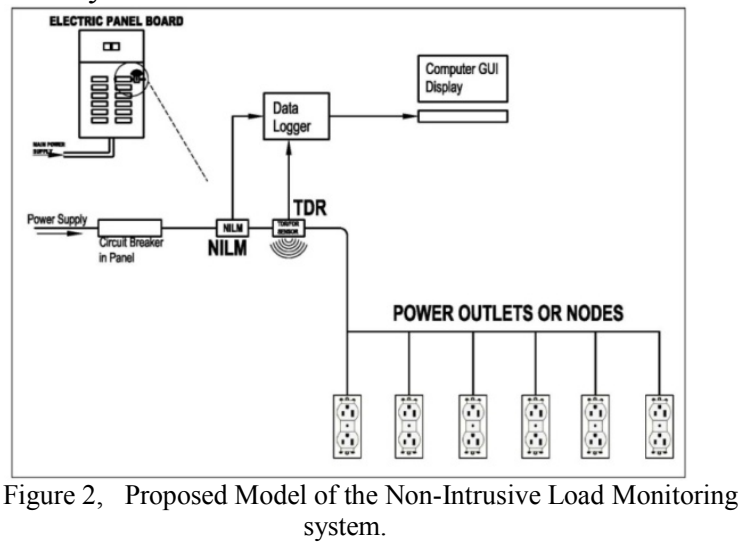




\section{A. Time Domain Reflectometry Theory}

The principle of time domain reflectometer is illustrated in fig. 3. A pulse signal $E_{0}^{i}$ is sent into the conductor segment $\left(Z_{1}\right)$, part of the signal is reflected $\left(E_{0}^{r}\right)$ back at the boundary 0 and a transmitted component $\left(E_{0}^{t}\right)$ propagates into the second segment $\left(Z_{2}\right)$.

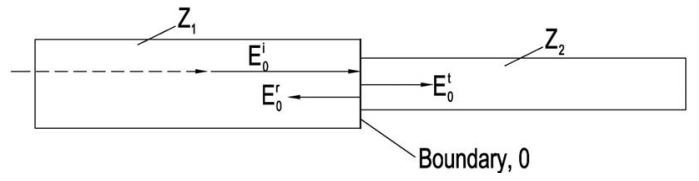

Figure 3, Transmission Line Analogue configuration for TDR.

The transmission line configuration shown in fig. 3, [7] the incident $\mathrm{E}_{0}^{\mathrm{i}}$, reflected $E_{0}^{r}$ and transmitted $E_{0}^{t}$ electric signal at the boundary 0 are related by:

$$
\begin{gathered}
E_{0}^{i}+E_{0}^{r}=E_{0}^{t} \\
\frac{E_{0}^{i}}{Z_{1}}+\frac{E_{0}^{r}}{Z_{1}}=\frac{E_{0}^{t}}{Z_{2}}
\end{gathered}
$$

Where $Z_{1}$, and $Z_{2}$ are the characteristic impedance of the transmission lines 1 and 2 respectively. Combining equations (1), (2) and eliminating $E_{0}^{t}$,

$$
E_{0}^{r}=\left(\frac{Z_{2}-Z_{1}}{Z_{2}+Z_{1}}\right) E_{0}^{i}, \quad E_{0}^{r}=\Gamma E_{0}^{i},
$$

Where $\Gamma$ is the reflection coefficient.

$$
\Gamma=\frac{E_{0}^{r}}{E_{0}^{i}}=\left(\frac{Z_{2}-Z_{1}}{Z_{2}+Z_{1}}\right)
$$

Dividing through (1), by $E_{0}^{i}$

$$
\begin{aligned}
& 1+\frac{E_{0}^{r}}{E_{0}^{i}}=\frac{E_{0}^{t}}{E_{0}^{i}}, \\
& 1+\Gamma=\tau
\end{aligned}
$$

Where $\tau$, is the transmission coefficient;

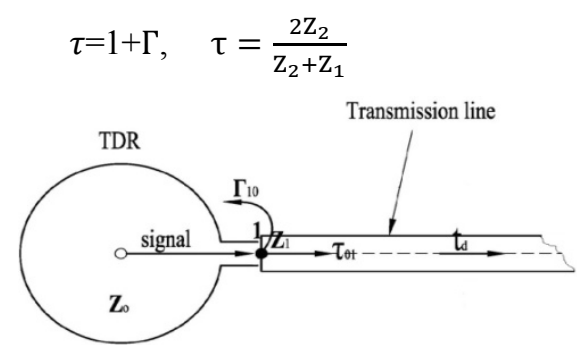

Figure 4, TDR signal on a transmission line.

Applying equations (3b) and (4b) to a TDR and a transmission line shown in fig. 4 , where the voltage signal is generated by the TDR,

$$
\begin{gathered}
\tau_{01}=1+\Gamma_{10} \\
\Gamma_{10}=\frac{Z_{1}-Z_{0}}{Z_{1}+Z_{0}},
\end{gathered}
$$

Where,

$\tau_{01}$ Is the transmitted signal from transmission line 0 to 1.
$\Gamma_{10}$ Is the reflected signal from 1 to 0 .

$\mathrm{Z}_{0}, \mathrm{Z}_{1}$ are the characteristic impedance of the TDR and line 1 respectively.

$T_{d}$ is the travel time or delay for transmitted and reflected signal. $T_{d}$ is dependent on the velocity of propagation (VOP) of the conducting medium and is the same for transmission and reflection on the transmission line.

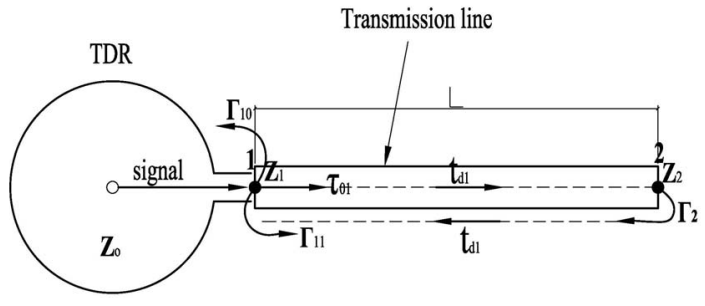

Figure 5, TDR - transmission line segment configuration

Consider the TDR - transmission line configuration shown in fig. 5;

$\tau_{01}$ is the transmitted signal from point $0-1$, travelling to point 2 with a time delay, $\mathrm{T}_{\mathrm{d}}=\mathrm{T}_{\mathrm{d} 1}$

$\tau_{10}$ is the transmitted signal from line 1-0 back to TDR with $T_{d}$ $=0$

$\Gamma_{10}$ is the reflected signal from 1 to 0

$\Gamma_{11}$ is the reflected signal about point 1 back to the transmission line

$\Gamma_{2}$ is the reflected signal at point 2 , travelling back to TDR with a time delay, $\mathrm{T}_{\mathrm{d}}=\mathrm{T}_{\mathrm{d} 1}$

$\mathrm{Z}_{0}, \mathrm{Z}_{1}, \mathrm{Z}_{2}$ are the impedance of TDR and the characteristic impedance per length at points 1 and 2 respectively.

\section{B. Preliminary Simulations and Results}

Fig. 6 shows a sample simulation setup for the TDR analysis. The conductor is a solid coated \# 14 AWG of characteristic impedance $0.0104 \mathrm{ohm} / \mathrm{m}$ and a VOP of 0.84 [18],[19].

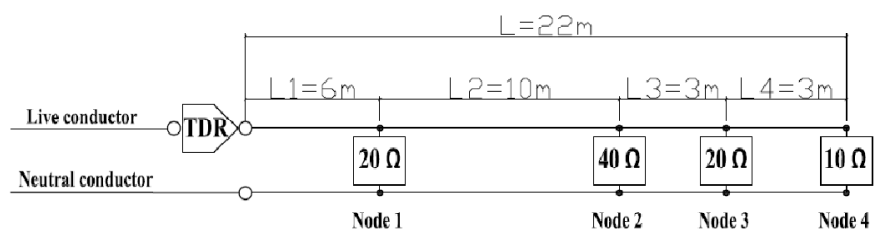

Figure 6, \#14 AWG conductor with characteristic impedance of $0.0104 \mathrm{ohm} / \mathrm{m}$ and VOP of 0.84 (Not drawn to scale).

Table 1, TDR - configuration data for the setup in fig. 6 .

\begin{tabular}{cccc}
\hline Node & $\begin{array}{c}\text { Interconnecting } \\
\text { conductor } \\
\text { Length/m }\end{array}$ & $\begin{array}{c}\text { Cumulative } \\
\text { Length from } \\
\text { TDR/m }\end{array}$ & $\begin{array}{c}\text { Total Impedance/ } \\
\boldsymbol{\Omega}\end{array}$ \\
\hline 1 & 6 & 6 & $0.0104 \times 6+20$ \\
\hline 2 & 10 & 16 & $0.0104 \times 10+40$ \\
3 & 3 & 19 & $0.0104 \times 3+20$ \\
4 & 3 & 22 & $0.0104 \times 3+10$ \\
\hline
\end{tabular}

Durham School of Architectural Engineering- UNL 
Since the velocity of propagation is the same for each segment (uniform conductor) the ratio of propagation from segment to segment will be 1 . Therefore the propagation delay, $T_{d}$ is simply given by;

$$
\mathrm{T}_{\mathrm{d}}=\frac{1}{2} \times(\text { length of segement }) \times \frac{0.84}{0.84}
$$

This delay will be measured by the TDR to calculate distance from nodes when there is a change in impedance at a node.

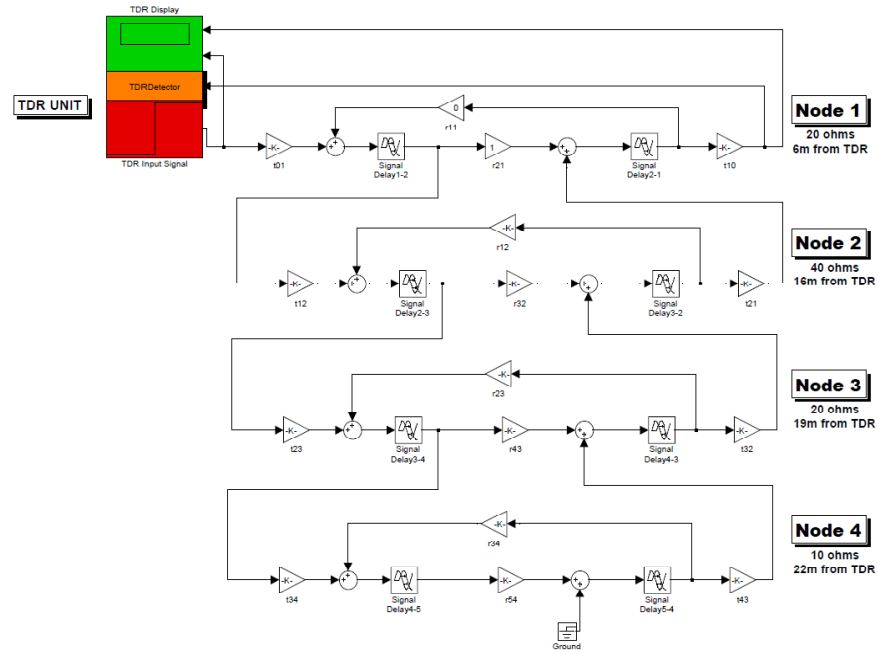

Figure 7, Simulink Block diagram of TDR setup in figure 6.

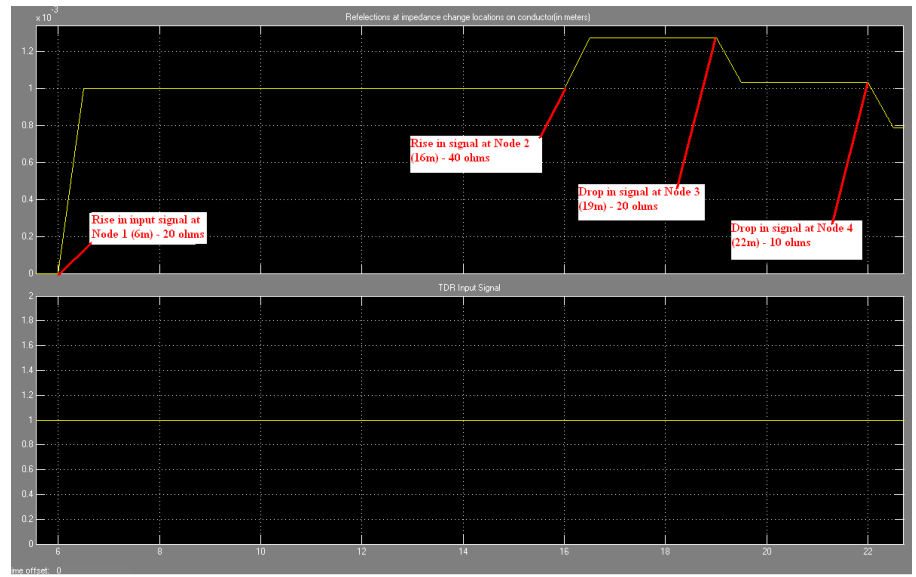

Figure 8, Simulated TDR display of nodes with connected loads.

From the simulated results, it can be seen that, the TDR will display a rise in signal amplitude when the change in impedance from one segment to the other is high and drops when the change is low. The various node locations are shown on the graph (fig. 8) as 6, 16, 19 and 22 meters, respectively from the TDR location.

\section{LOAD PREDICTION}

Recently, more industry and academic research has been focused on controlling energy consumption and improving the energy efficiency of the built environment. In the past, different application-specific methods have been investigated to understand, among other things, how loads affect power consumption, power quality, efficiency, reactive power compensation, and system planning. The purpose of the load prediction aspect of this research is to understand the characteristic-load consumption. In this paper, a neural network (NN) methodology will be employed to predict electrical loads for typical commercial and residential applications. The neural network will provide a kilo watt $(\mathrm{kW})$ Model. This model employs past trained data and serves as a baseline using past trained data to reflect an increase or decrease in energy use. The real-time monitored $\mathrm{kW}$ will be compared to the model $\mathrm{kW}$ (baseline). The difference between the two should reflect the potential energy savings. In other words, the Model $\mathrm{kW}$ will make it easier for engineers to define acceptable performance thresholds. The following section will introduce NN for Electrical loads in order to enable researchers to estimate the energy consumption for a specific locale. Non-intrusive load monitoring (NILM) is considered to be one of the earliest approaches to nonintrusive monitoring. Engineers could determine the operating schedule of electrical loads in the target system from measurements made at a centralized location. A similar approach is taken for EchoResonance Load Monitoring (ERLM), Sign-Up Load Registration (SULR), and developing a library and taxonomy of load signatures [19-25]. The following steps are used to define the load state, load type and prediction process:

- Data acquisition or preprocessing data

- Data processing

- $\quad$ Statistical analysis

- Neural Network Design (Model kW Design)

- Addressing energy exploitation using load location Identification and the created model.

\section{A. Defining the Load Prediction:}

A real-time power monitoring system was developed for data acquisition purposes. A Current and Voltage transducer was integrated with the Op amps and microcontroller and installed into the panel. Using this power sensor, current and voltage waveforms are sampled every 100 micro seconds, these samples (digital values) are sent to the computer via a serial port using the RS232 protocol. This process is used to measure and represent the load characteristics. A signal processing technique and estimation algorithm will be created for signal filtering, signal disaggregation, and load recognition. Previously, different methods have been used to improve the energy efficiency of the system and reduce costs. This approach analyzes the energy consumption. The concept of energy modeling for the purposes of this paper is based on load monitoring. $\mathrm{kW}$ model (Neural Network) will be trained and used as a baseline or a reference. The input for the neural network will be a historical energy data from an existing test home. The output will be estimation for the consumption data the following year. Load disaggregation is the next step in the prediction process. The next step in the load prediction process is load disaggregation. It involves the following:

\section{- Data acquisition:}

Data acquisition is also called pre-processing. In this method, historical energy data and weather patterns will be captured at a fixed sample rate and stored for the next process. 
The energy demand (in kilowatts) will be sampled and stored for every fifteen minutes. The weather parameters will be generated from the local weather channel. Readings of both data will be collected every minute. The outside air temperature (OAT) and outside air relative humidity (ORAH) are two parameters will be employed in training neural network model. Other forms of data will be hours of the day and holidays. Normalization will be applied for all of the previously stored parameters. Table 2 , shows a sample stored data.

Table 2: List of Neural Network Parameters.

\begin{tabular}{ccccc}
\hline Minutes & $\begin{array}{l}\text { Holidays- } \\
\text { Weekend }\end{array}$ & OAT & ORAH & Load(kW) \\
\hline 1395 & 1 & 37.6 & 72 & 4176 \\
1410 & 1 & 37.5 & 73 & 4185.6 \\
1425 & 1 & 37.8 & 73 & 4195.2 \\
0 & 0 & 37.6 & 73 & 4185.6 \\
---- & ---- & ---- & ---- & ---- \\
---- & ---- & ---- & ---- & ---- \\
1410 & 0 & 44.3 & 98 & 3993.6 \\
1425 & 0 & 44.5 & 98 & 3993.6 \\
\hline
\end{tabular}

- Data Processing Model: Because of the massive amount of data and the changed characteristic curve for the loads, the signal data must be conditioned and re-sampled. In summary, a statistical analysis will be made and redundant data deleted.

- Design Neural Network: The artificial neural network (ANN) will be trained and tested using processed data from previous steps. This research will be using the Multi-layer-Feed forward [26] neural network in the design process.

- Fault detection: In future studies, the fault mechanism will be created along with algorithms that can detect the potential energy savings based on a comparison between the actual monitored $\mathrm{kW}$ and the Model $\mathrm{kW}$. Measurements other than the Model kW will be used when the load number increases [27].

\section{B. Design of the Neural Network}

This research focuses on the Multi-Layer Feed Forward Network commonly known as the Multi-Layer Perception (MLP) Network. It consists of one or more hidden layers with computational nodes that are correspondingly called hidden neurons. The purpose of the hidden neuron is to increase the computation between the input and output core layers in some useful manner. The input signal is applied to the neurons in the second layer while the output signal of the second layer is used as an input for the third layer, and so on for the rest of the network. Fig. 9 represents the MLP network topology.

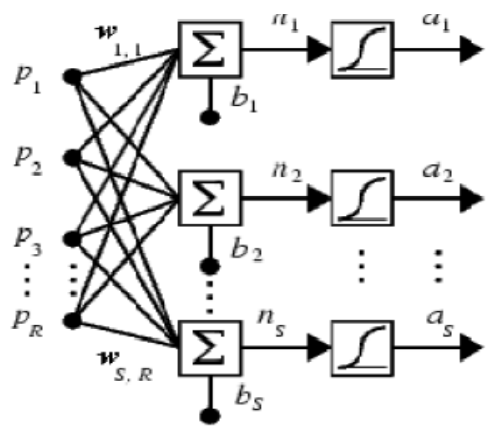

Figure 9: Topology of an MLP where R is the Number of Elements in the Input Vector, $\mathrm{S}$ is the Number of Neurons in the Layers, and Wij are the Weighting Factors between the Different Layers.

The MLP operates in two steps: Training and testing. Training functions minimize the difference between the MLP outputs and the desired values of the network. At the completion of the training state the neural weights will be frozen and new input data used to create a suitable output [27].

\section{1) Training and Testing Patterns of the Neural Network}

Using the trial and error method, the training process achieved the optimal behavior of the network. The fastest training function is trainlm, which is also the default training function of the feed forward network. In future research, the investigators plan to test other methods such as the quasiNewton method and trainbfg. Finally, 2 hidden layers with feed forward activity and 20 neurns were chosen. The basic traning data included a sample size of 3100 . After achieving the optimal training, the network will be tested for load prediction accuracy. For the purpose of testing, a $15 \%$ or $20 \%$ deviation out of the load samples was applied to the data content (table 2) for a typical residence. The results from the calculation were compared with the Percent Relative Error (PRE):

$$
\varepsilon_{\mathrm{r}}(\%)=\left[\sum_{\mathrm{i}=1}^{\mathrm{N}}\left(\mathrm{P}_{\mathrm{ti}}-\mathrm{P}_{\mathrm{i}}\right)^{2}\right]^{0.5}
$$

where $\mathrm{N}$ represents the number of samples, $\mathrm{P}_{\mathrm{ti}}$ is the load percentage calculated from the ANN model, and $\mathrm{P}_{\mathrm{i}}$ is the actual percentage of the load i. Fig. 10 is a graph that gives the best performance of the trained network. The mean square error is less than $5 \%$, or an acceptable error.

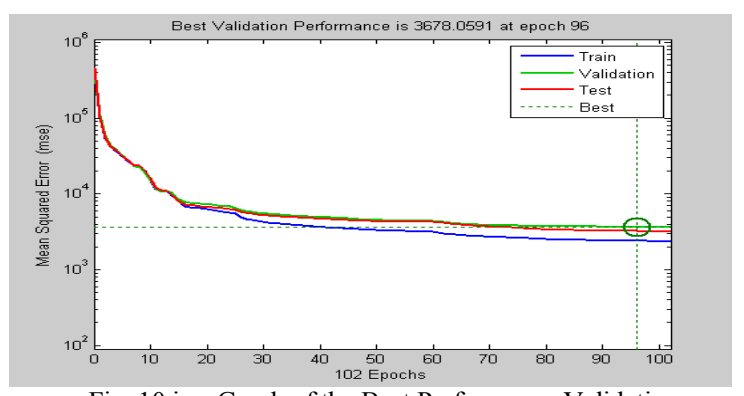

Fig. 10 is a Graph of the Best Performance Validation 


\section{2) Results of the Neural Network}

The neural network or model will predict the amount of energy used in the future. Tests were conducted to determine the sizing possibilities for the Model. When combined, the data for the relative humidity, temperature, and holidays give better results and create a more reliable $\mathrm{kW}$ Model. Fig 12 below gives a comparison between the predicted and measured data.

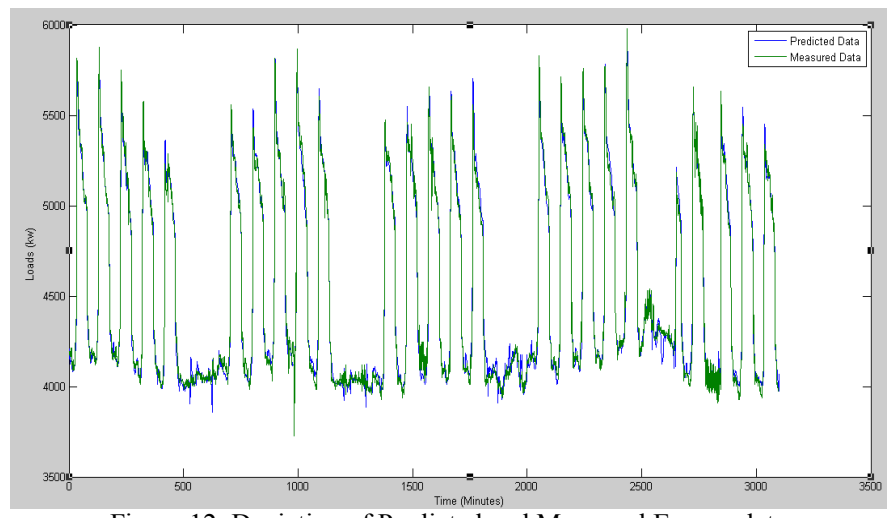

Figure 12 Deviation of Predicted and Measured Energy data

\section{Addressing Energy Exploitation:}

In future studies, it is hoped that the proposed methods will lower energy spending by $15-25 \%$ spanning the lifecycle of most home electronics. The load location identification method can be combined with the $\mathrm{kW}$ Model to detect the energy saving potential and also locate the source of the savings. This can be accomplished using only minimal additional hardware and software.

\section{CONCLUSION}

In this paper, smart home technologies are being introduced to conserve energy in the built environment for Electrical Vehicles. The identification methods enabled by the TDR and Model technologies will reduce the need for hardware additions to the existing electrical circuitry in the built environment.

Preliminary findings from the simulations indicate that a sensor technology can be developed with the capacity to upgrade the existing electrical systems in the built environment. This technology will not only reduce the costs associated with upgrading, but will increase the energy efficiency in the built environment and eventually reducing greenhouse gas emissions $\mathrm{CO}_{2}, \mathrm{NO}_{2}$, etc. in the electrical power generation process.

\section{REFERENCES}

[1] Williams, Eric D., \& Matthews, H. Scott., "Scoping the Potential of Monitoring and Control Technologies to Reduce Energy use in Homes," Proceedings of the 2007 IEEE International Symposium on Electronic \& Environment, May 2007, pp. 239-244.
[2] U.S. Green Building Council, "Green Building Facts." U.S. Green Building Council. www.usgbc.org/ShowFile.aspx?DocumentID=5961, Accessed 7-21-2010.

[3] Chevron's energy efficiency and conservation, http://www.chevron.com/globalissues/energyefficiencyconservation/, Accessed 7-21-2010.

[4] Karen Ehrhardt-Martinez, Kat A. Donnelly, \& John A. "Skip" Laitner, "Advanced metering Initiatives and Residential Feedback Programs: A Meta-Review of Household Electricity-Saving Opportunities," American Council for an Energy-Efficient Economy, report Number E105, June 2010.

[5] Intelli-plug, http://www.ethicalsuperstore.com/products/oneclick/energysaving-intelli-plug-dsk-105/\#product_ethics, 2008.

[6] Sticord plugs, http://www.homeqn.com/entry/sticord-power-saver-plugpromises-to-conserve-energy, 2010.

[7] Vulcan Surge Protector, http://vulcantechnology.com/products/.

[8] Banting John, Fredrick and Mcbee Bruce W. (2010). " Power Line Energy Harvesting Power Supply" US Patent Application Publication No. US 2010/0084920 A1.

[9] Martin Hartebrodt and Kabitzsch, K. (2004). "Fault Detection in Fieldbuses with Time Domain Reflectometry", IEEE Africon.

[10] Guangming Song, Fei Ding, Weijuan Zhang, and Aiguo Song (2008). "A Wireless Power Outlet System for Smart Homes" IEEE Transactions on Consumer Electronics, Vol. 54, No. 4.

[11] You Chung Chung, Nirmal N. Amarnath, Cynthia M. Furse, and John Mahoney (2009), "Capacitance and Inductance Sensors for locating of open and Short Circuited Wires", IEEE Transaction on Instrumentation and Measurement, Vol. 58. No. 8.

[12] Paul K. Kuhn, Cynthia Furse, and Paul Smith (2006). "Loacting Hidden Hazards in Electrical Wiring" Aged Electrical Systems Research Application Symposium.

[13] IEEE Power Engineering Society, (2004). IEEE Guide for Power-Line Carrier Applications.

[14] Yu-Ju Lin, Haniph A. Latchman, Richard E. Newman, and Srinivas Katar (2002). " A Power Line Communication Network Infrastructure For The Smart Home" IEEE Wireless Communications Vol. 9, No. 6.

[15] Shichuan Ma, Yaoqing (Lamar) Yang, Hamid Sharif, Yi Qian, and Mahmoud Alahmad (2010). " Energy Harvesting and Its Challenges in Smart Grid ". unpublished.

[16] Fawwaz T. Ulaby, Eric Michielssen, Umberto Ravaioli., "Fundamentals of Applied Electromagnetics ", 6th ed, Prenice Hall, Boston, 2010.

[17] Belden, "Detailed Specifications and Technical Data" 14 AWG solid cable, pp 2, 2011.

[18] NFPA 70. "National Electrical Code", 2011.

[19] Shaw, S., S. Leeb, L. Norford and R. Cox, " Nonintrusive load monitoring and diagnostics in power systems," IEEE Trans. On Instrumentation and Measurement, Vol 57, issue 7, 2008, pp 1445-1454

[20] G. w. Hart, "Nonintrusive appliance load monitoring," Proc. Of the IEEE, Vol. 80, pp. 1870-1891. Dec, 1992.

[21] F. Sultanem, "Using appliance signatures for monitoring residential loads at meter panel level," IEEE Transactions on Power Delivery, Vol. 6, pp. 1380-1385, 1991.

[22] C. Laughman, K Lee, R. Cox, S. shaw, S. Leeb, L. Norford and P. Armstrong, "Power Signature analysis, "Power and Energy Magazine, IEEE, Vol. 1, pp. 56-63, 2003

[23] W K Lee, G S K Fung, H Y Lam, F H Y Chan, M. Lucente, “ Exploration on Load signatures", International conference on electrical Engineering (ICEE), July 2004, Japan.

[24] K. H. Ting, Mark Lucente, George S. K. Fung, W. K.. Lee and S. Y. R. Hui, "A taxonomy of Load Signatures for Single-Phase electric Appliances," IEEE PESC, 12-18 June 2005, Brazil .

[25] J. Duan et al. "Neural Network Approach for Estimating of Load comostion", 2004.

[26] Load signature Study-Part I: Basic Concept, Structure, and Methodology " Jian Liang, Simon K.k. Ng, Member, IEEE, Gail Kendall, and John W.M.Cheng", Member,IEEE

[27] L.Fausett, Fundamentals of Neural Networks, prentice-Hall Inc.,1994. 